\title{
Reseña: Novillo, W. 2018. Fórmulas estructurales de la música comercial. Cuenca, Ecuador: Universidad de Cuenca, 140 pp.
}

Review: Novillo, W. 2018. Structural formulas of commercial music. Cuenca,

Ecuador: University of Cuenca, 140 pp.

José Luis Crespo Fajardo

Universidad de Cuenca, Ecuador (luis.crespo@ucuenca.edu.ec)

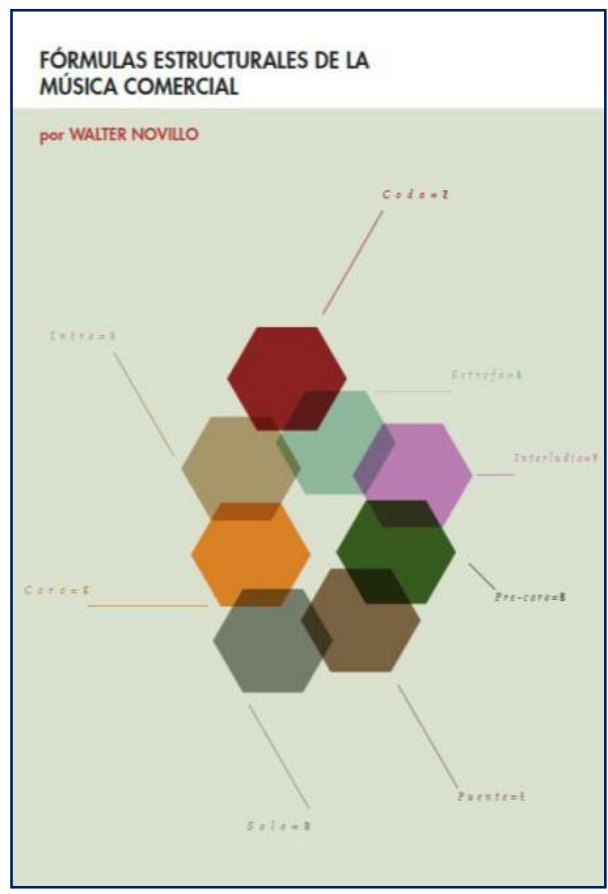

Dentro de la colección Objetos singulares, dedicada especialmente a manuales de formación artística, la Universidad de Cuenca (Ecuador), ha publicado recientemente Fórmulas estructurales de la música comercial, un volumen de 140 páginas que recoge análisis sobre la estructura de 500 temas populares a nivel internacional desde la década de los 60’s en adelante.

En contraposición a la música clásica, en la actualidad hay un amplio abanico de expresiones musicales que, por sus procesos de difusión y márquetin, conocemos como música comercial. Sin embargo, no sólo la define su cariz altamente consumista y de popularidad masiva. En realidad, suele ser material de buena calidad, lo que sin duda contribuye a su éxito. 
El libro estudia una selección de medio millar de hits con el fin de revelar sus fórmulas intrínsecas, sirviendo así de referencia sobre estructuras y composición para estudiantes y productores musicales.

El universo de temas escogidos no representa la integridad de la producción que la industria cultural global ha generado en el periodo de estudio, pero es un interesante acercamiento para experimentar los parámetros del análisis: intro, interludio, estrofa, coda, puente, coro, pre-coro y solo.

Las obras examinadas proceden de los primordiales mercados comerciales: Estados Unidos, Reino Unido, México, Argentina, España... No obstante, también se incluye un porcentaje de obras de Ecuador y Corea del Sur. La selección va desde clásicos como Air Supply, Toto, Pink Floyd, The Beatles, AC/DC, Bruce Springsteen, U2 y Mecano, hasta obras de músicos contemporáneos como Chistina Perri, Justin Bibier, Bruno Mars o el colombiano Andrés Cepeda. Asimismo, resulta valioso el estudio de bandas ecuatorianas como Basca, La Doble o Bajo Sueños.

Cabe mencionar que los resultados, presentados en forma estadística, demuestran que un altísimo porcentaje de obras poseen un patrón estructural único, lo cual rebate el tópico (al menos en cuanto a estructuras compositivas) de que la música comercial carece de originalidad.

En definitiva, Fórmulas estructurales de la música comercial es un manual sumamente útil que brinda una guía a los jóvenes compositores para a seguir en el camino de la creatividad, partiendo de un hondo conocimiento de lo que han ejecutado las vigentes y anteriores generaciones de músicos de éxito.

\section{Biografía / Biografia / Biography}

José Luis Crespo Fajardo. Doctorado (PhD) en Bellas Artes por la Universidad de Sevilla (España). Máster Universitario en Estudios Pedagógicos Avanzados por la Universidad de La Laguna (España). Profesor de la Facultad de Artes y de la Facultad de Arquitectura de la Universidad de Cuenca (Ecuador) 